\title{
Titanium dioxide nanoparticle incorporated PVDF-HFP based composite membrane for direct methanol fuel cell application
}

\author{
M. A. Karim \\ School of Energy, Materials and Chemical Engineering, Korea University of Technology and Educcation, \\ Byongcheon-myeong, Cheonan 330-708, Republic of Korea.
}

Received: 16 September 2020

Revised: 29 December 2021

Accepted: 31 March 2021

DOI: https://doi.org/10.3329/bjsir.v56i1.54319

\begin{abstract}
Two composite polymeric membranes were synthesized using poly vinylidene fluoride-hexafluoroprropylene (PVDF-HFP) host in polyvinyl alcohol and with or without $\mathrm{TiO}_{2}$ nanoparticles as a porous substrate. The structure of the membranes was PDVF-HFP/PVA and PVDF-HFP/PVA/TiO . The composition of the synthesized membranes was analyzed by FTIR spectrum. The porosity of the polymer membranes were measured by immersing the membranes into n-butanol. The conductivity of the composite membranes was determined by impedance spectroscopy and the methanol permeability of the membranes was obtained from diffusion experiments. The surface morphology images were investigated by scanning electron microscope(SEM). The SEM image of the composite membrane incorporated with $\mathrm{TiO}_{2}$ has many pores which increased the conductivity of the membrane as compared to non $\mathrm{TiO}_{2}$ incorporated one. The composite membrane with $\mathrm{TiO}_{2}$ showed a good balance between proton conductivity and methanol permeability. The cell with $\mathrm{PVDF}-\mathrm{HFP} / \mathrm{PVA} / \mathrm{TiO}_{2}$ composite membrane showed higher power density.
\end{abstract}

Keywords: Poly vinylidene fluoride-hexafluoroprropylene; Polyvinyl alcohol; Composite membranes; Nanoparticles; Direct methanol fuel cell (DMFC).

\section{Introduction}

Realizing the depleting natural energy sources with increasing energy consumption, there is a compulsion to find non-conventional energy sources for today's science and technology which will cater to the increasing energy demand in future. Recently, scientists are looking for fuel cells as one of the possible options because they are relatively efficient and clean energy producers. Among the fuel cells, direct methanol fuel cell (DMFC) is a promising candidate. Some of the attractive characteristics of the DMFC are portability, emission-free clean energy, low cost, low temperature operation, high efficiency and fuel safety (Dillon et al., 2004; Patil et al., 2004; Kumar et al., 2008a). Commercially available membranes in DMFC are still Nafion membranes, due to their excellent proton conductivity, high thermal resistance and chemical stability; however, high methanol permeability and cost are the main disadvantages for using this kind of membrane (Kumar and Nahm et al., 2008b). An increase in the methanol permeability leads to poisoning of cathode catalysts, increased reaction overpotential due to the mixed potential, loss of fuel, and emissions of low-concentration toxic materials (Shen et al., 2006; Yamauchi et al., 2007). Therefore, several attempts have been made to develop new electrolyte polymeric membranes that can be used as an alternative membrane for DMFCs (Rhim et al., 2004; Cai et al., 2017; Miyake et al., 2017; Fujiyama et al., 2008; Tian et al., 2007; Noshay et al., 1976; Chen et al., 2012; Bahlakeh et al., 2013; Chae et al., 2014; Qing et al., 2005; Yue et al., 2015; Xu et al., 2007; Liu et al., 2015; Iizuka et al., 2013; Cleemann et al., 2013; Wang et al., 2012; Hwang et al., 2014; Jia et al., 2015; Staiti et al., 2001). 
For example, Polybenzimidazole composite, Fluorine-free sulfonated aromatic polymers (Miyake et al., 2017), Sulfonated Poly (aryl ether ketone) Random Copolymers (Fujiyama et al., 2008), perfluorosulfonic acid (PFSA) membranes (Tian et al., 2007), sulfonated polysulfone (SPSF) (Noshay et al., 1976), sulfonated polyether sulfone (SPES) (Chen et al., 2012), sulfonated poly (ether ether ketone) (SPEEK) (Bahlakeh et al., 2013; Chae et al., 2014), polybenzimidazole (PBI) (Qing et al., 2005; Yue et al., 2015; $\mathrm{Xu}$ et al., 2007), and polyvinylidene fluoride (PVDF) (Liu et al., 2015), phosphoric acid (PA) doped polybenzimidazole (PBI) composite membranes (Iizuka et al., 2013; Cleemann et al., 2013; Wang et al., 2012; Hwang et al., 2014), nanoparticle enhanced polymers (Jia et al. 2015; Staiti et al., 2001), sulfonated poly (vinyl alcohol) (Prakash et al., 2002), polystyrene sulfonic acid crosslinked within a poly (vinylidene fluoride) matrix (Xing et al., 2004), and sulfonated poly (etherether ketone) (Li et al., 2003) have been developed for use in DMFCs.

Among the various polymers, poly(vinylidene fluoride-co-hexafluoropropylene) (PVDF-HFP) attracts researchers for its crystalline and amorphous nature, in which the amorphous phase promotes the ionic conductivity and the crystalline nature influences the mechanical strength of the membrane (Dutta et al., 2014). Poly (vinylidene fluoride-co-hexafluoro propylene) is a promising polymer for the fabrication of membranes in direct methanol fuel cells, because of its low methanol permeability, high mechanical integrity and significantly low cost compared to conventionally used Nafion membrane. However, low proton conductivity has hindered its independent use; therefore, most studies on this prospective copolymer have been done by using it in conjunction with Nafion. Nevertheless, partial sulfonation of this copolymer has resulted in increased proton conductivity while maintaining its low methanol permeability. Therefore, it seems appropriate that blending this sulfonated copolymer with a second low cost component, which can complement its low conductive nature, can result in PEMs with high selectivity (Kumar et al., 2009).

In this study, in order to improve membrane affinity towards water rather than methanol, polyvinyl alcohol is being incorporated into the polymer which has $-\mathrm{OH}$ as a functional group. Poly vinyl alcohol (PVA) is a cheap polymer and has a high selectivity of water to alcohol to reduce the methanol permeability. Moreover, the functional $-\mathrm{OH}$ groups of PVA have the potential for cross-linking which satisfy the stability parameter of the membranes (Martinelli et al., 2006; Aricò et al., 2005). On the other hand, the interactions between $\mathrm{TiO}_{2}$ nanoparticles surface and polymer chains are recently considered as a promising mechanism for the increase in ionic conductivity (Kumar et al., 2010). As far as my knowledge goes, only a few attempts have been made for modification of PVdF-HFP for DMFCs application (Kumar et al., 2009; Li et al., 2003).

Therefore, in this study, PVDF-HFP was used to make polymeric composite membranes as PVDF-HFP/PVA and PVDF-HFP/PVA/TiO 2 and characterized their performances for DMFCs application.

\section{Materials and methods}

Poly (vinylidene fluoride-co- hexafluoropropylene) (PVDF-HFP) (Kynar Flex 2801, Arkema, Japan), Poly vinyl alcohol (PVA) (Aldrich, Molecular weight: 98,000), Titanium(IV)oxide (Aldrich, nanopowder, $\sim 21 \mathrm{~nm}$ particle size), N,N-Dimethyl Formamide (Sigma) were utilized in the study.

\section{Membrane preparation}

Two membranes were prepared such as: 1) The PVDF-HFP copolymer (7 wt \%) was dissolved in dimethyl formamide (DMF) and mixed well by stirring. After that of PVA (4.6 wt $\%$ ) was added and stirred until it mixed (Dutta et al., 2014). The mixture was magnetically stirred for $24 \mathrm{~h}$ at $60^{\circ} \mathrm{C}$. The concentrated solution was cast as a film onto a glass substrate. 2) The PVDF-HFP copolymer (7 wt \%) was dissolved in dimethyl formamide and mixed well by stirring. After that of PVA (4.6 wt \%) was added and stirred until it mixed (Dutta et al., 2014) Finally, TiO nanoparticles (2 wt $\%$ ) was added and stirred for $24 \mathrm{~h}$ at $60^{\circ} \mathrm{C}$. The concentrated solution was cast as a film onto a glass substrate. Then these two films were kept at $80^{\circ} \mathrm{C}$ for $12 \mathrm{~h}$ in vacuum in order to evaporate the solvent. Then, the films were soaked in double distilled water at $60^{\circ} \mathrm{C}$ for $20 \mathrm{~h}$ to remove the PVA content from the film and dried at $100^{\circ} \mathrm{C}$ in vacuum for $10 \mathrm{~h}$ to remove the traces of water. The dried membranes were soaked in $6 \mathrm{M}$ sulfuric acid at $60^{\circ} \mathrm{C}$ for $24 \mathrm{~h}$ for functionalization (Kumar et al., 2009). The resulting membranes were dried and subjected to characterization. Schematic diagram of preparation procedures for $\mathrm{PVDF}-\mathrm{HFP} / \mathrm{PVA} / \mathrm{TiO}_{2}$ and PVDF-HFP/PVA membranes was presented in Fig. 1 and a schematic diagram of working principles of DMFCs was shown in Fig. 2 respectively.

\section{Characterization of membrane}

FT-IR was recorded at room temperature in the region 400-4000 $\mathrm{cm}^{-1}$ by Perkin Elmer spectrum 1000 with a resolution of $4.0 \mathrm{~cm}^{-1}$ to confirm the structure of blending 


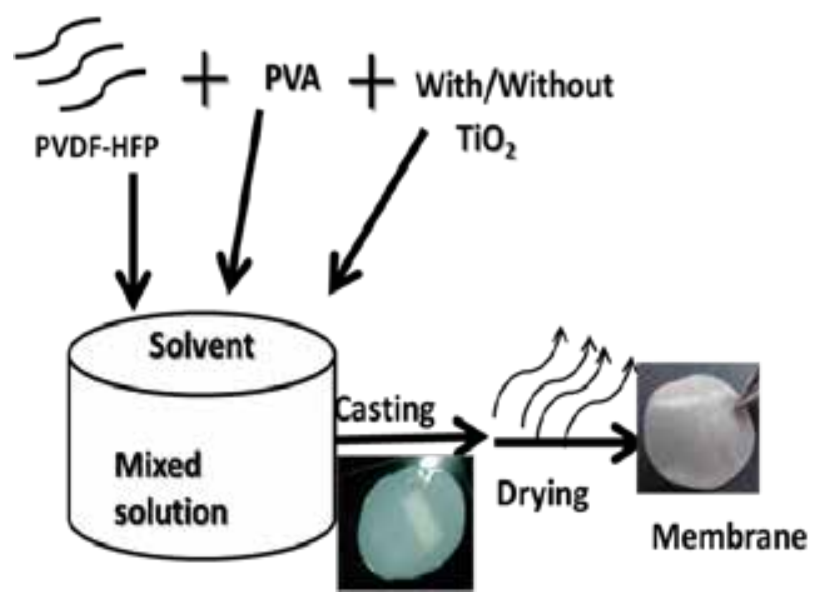

Fig. 1. Schematic diagram of preparation procedures for PVDF-HFP/PVA and PVDF-HFP/PVA/TiO, embranes

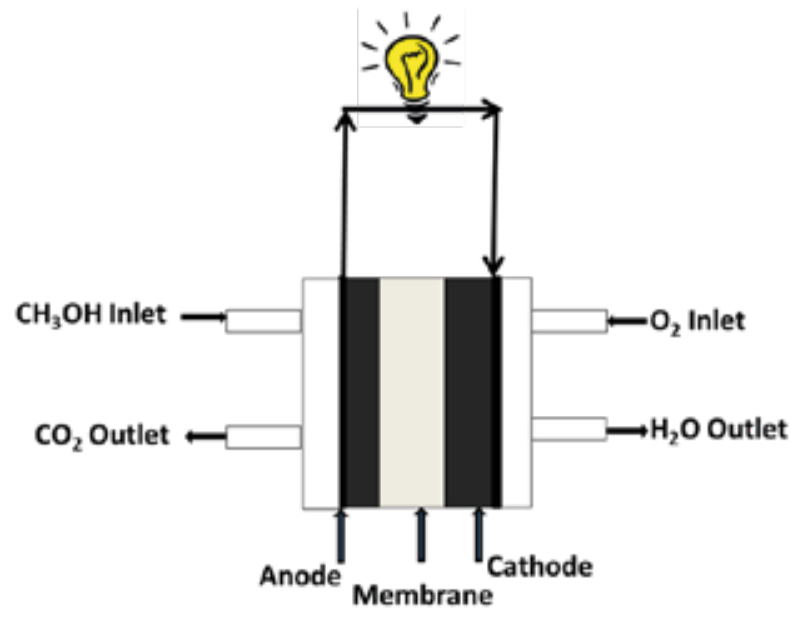

Fig. 2. A schematic diagram of working principles of DMFCs

polymeric membranes. A sample was made by dissolving small amount of membrane in chloroform solvent and a drop was place in sample dice, which was later placed in sample holder to measure the FTIR analysis. The porosity of the polymer membranes was measured by immersing the membrane into n-butanol for $1 \mathrm{~h}$ and weighing the membrane before and after absorption of the n-butanol. The porosity was calculated using the following equation (Zhng et al., 2009; Kumar et al., 2008).

$$
P(\%)=\frac{\frac{M_{b}}{\rho_{b}}}{\frac{M_{p}}{\rho_{p}}} \times \frac{M_{b}}{\rho_{b}}
$$

where $\mathrm{p} \%$ is porosity of the membrane, $M_{p}$ is mass of the membrane, $M_{b}$ is the mass of absorbed n-butanol, $\rho_{p}$ is the density of the membrane and $\rho_{b}$ is the density of n-butanol.

The membranes were soaked in $6 \mathrm{M}$ sulfuric acid solution at $60^{\circ} \mathrm{C}$ for $24 \mathrm{~h}$ for the activation of the electrolyte membrane(Kumar et al., 2009). After the excrescence of the solution at the surface of the polymer electrolyte, the membrane was dried and weighed.

$$
\operatorname{Aciduptake}(\%)=\frac{W_{w e t}-W_{d r y}}{W_{d r y}} \times 100
$$

where $\mathrm{W}_{\text {wet }}$ and $\mathrm{W}_{\text {dry }}$ denote the mass of wet and dry samples, respectively.

The proton conductivity of the samples in the transverse direction was measured by the AC impedance spectroscopy technique over a frequency range of $1-10^{6} \mathrm{~Hz}$ with oscillating voltage $10 \mathrm{mV}$, using a frequency response analyzer (FRA) (Autolab PGSTAT20). The membranes were clamped between two blocks of stainless steel electrodes with diameter $5 \mathrm{~mm}$. Before the test, the membranes were dipped in water until they were sufficiently wet and compressed tightly between the blocking electrodes. The conductivity $(\sigma)$ of the samples was calculated from the impedance data, using the relation.

$$
\sigma=\frac{d}{R S}
$$

where $\mathrm{d}$ and $\mathrm{S}$ represent the thickness of the samples and the face area of the electrode respectively, and $\mathrm{R}$ is derived from the intersection of the beeline at high frequency with the $\operatorname{Re}(z)$ axis on a complex impedance.

The methanol permeability was determined using a diaphragm diffusion cell (Yamauchi et al., 2007; Martinelli et al., 2006). The cell consisted of two identical compartments $(25 \mathrm{ml})$ separated by the test membranes. One compartment was filled with a solution of methanol (1M) and the other was filled with deionized water. Prior to testing, the membranes were hydrated in deionized water for at least $24 \mathrm{~h}$. Both compartments were magnetically stirred during the permeation experiment. The concentration of methanol in 
deionized water compartment versus time was measured using gas chromatography (Tianmei T9700). The methanol permeability was calculated from the slope of the straight-line plot of methanol concentration versus permeation time. The data was collected from room temperature to $80^{\circ} \mathrm{C}$.

The membranes were soaked in deionized water for $24 \mathrm{~h}$ before the preparation of membrane electrode assemblies (MEAs). Catalyst slurries were prepared by mixing 2-propanol solution, and 20\% $\mathrm{Pt} / \mathrm{C}$ for cathode ink and $60 \%$ $\mathrm{PtRu} / \mathrm{C}$ for anode ink supplied by E-TEK. For fabrication of MEA, the catalyst slurry was coated on carbon paper (TORAY, Japan) for the electrode substrate. The Pt loadings were approximately $1 \mathrm{mg} / \mathrm{cm}^{2}$ and $2 \mathrm{mg} / \mathrm{cm}^{2}$ for anode and cathode, respectively. The effective electrode area of the single cell was $4.0 \mathrm{~cm}^{2}$. As a fuel $2 \mathrm{M} \mathrm{CH}_{3} \mathrm{OH}$ was used and delivered at $5 \mathrm{ml} / \mathrm{min}$ by a micropump as well as theoxygen pressure was maintained $0.2 \mathrm{MPa}$ at $50 \mathrm{ml} / \mathrm{min}$. The data was collected at a temperature of $80^{\circ} \mathrm{C}$.

\section{Results and discussion}

The FTIR spectra are an important tool to characterize and analyze the structural changes in polymer, to identify
$-\mathrm{CH}=\mathrm{CF}$ - skeletal breathing of PVDF-HFP polymer. For the sulfuric acid entrapped membranes, the observed peaks are attributed as follows: The hydronium ion $\left(\mathrm{H}_{3} \mathrm{O}^{+}\right)$formation in the membrane is found at $3409 \mathrm{~cm}^{-1}$ and $3418 \mathrm{~cm}^{-1}$ respectively. This peak should not be of water itself, but is attributed to hydronium ion, which can combine with coexisting $\mathrm{RSO}_{3}$ - to produce $\mathrm{RSO}_{3} \mathrm{H}$ and release water with the progress of dehydration in the membrane (Kumar et al., 2009). From this IR spectrum, it is clear that sulfuric acid electrolyte has been completely entrapped in the porous PVDF-HFP polymer matrix and confirms the structural configuration of the composite membrane. Thus, a strong interaction occurred between the host polymeric units, PVA and the sulfuric acid that guaranteed the durability of the fabricated porous membranes.

Porosity of the composite membrane was examined by n-butanol absorption (Dutta et al., 2014; Wu et al., 2005). The maximum porosity of the composite membrane was obtained $55 \%$ in this study which favors the high acid absorption as shown in Table I.

The ionic conductivity of the composite membrane is shown in Fig. 4. Ion transport of these membranes depends on the

able I. Composition of membranes (wt \%), acid absorption (wt \%), conductivity properties and structure of composite polymer membranes

\begin{tabular}{llllll}
\hline $\begin{array}{l}\text { PVdF }- \\
\text { HFP }\end{array}$ & PVA & $\mathrm{TiO}_{2}$ & $\begin{array}{l}\text { Acid } \\
\text { absorption } \\
(\mathrm{wt} \%)\end{array}$ & $\begin{array}{l}\text { Conductivity } \\
(\mathrm{wt} \%)\end{array}$ & $\begin{array}{l}\text { Structure of composite } \\
\text { membrane }\end{array}$ \\
\hline 7 & 4.6 & - & 58 & 0.010 & $\mathrm{PVDF}-\mathrm{HFP} / \mathrm{PVA}$ \\
7 & 4.6 & 2 & 62 & 0.025 & $\mathrm{PVDF}-\mathrm{HEP} / \mathrm{PVA} / \mathrm{TiO}_{2}$ \\
\hline
\end{tabular}

functional groups, interactions and complexation of polymer composite. The vibrational bands of PVDF-HFP polymer at $704 \mathrm{~cm}^{-1}$ (- $\mathrm{CH}_{2}$ rocking vibration), $742 \mathrm{~cm}^{-1}$ (-CF 2 stretching vibration) belong to crystalline nature of VDF units of the polymer. The transmittance peaks at $1024 \mathrm{~cm}^{-1}, 1063 \mathrm{~cm}^{-1}$, $1101 \mathrm{~cm}^{-1}$ indicate $\mathrm{CF}_{2}$ symmetric stretching and $1232 \mathrm{~cm}^{-1}$ asymmetric stretching of PVDF-HFP polymer peaks which are found to be disappeared on addition of $\mathrm{TiO}_{2}$. The reason is because of weak interaction between $\mathrm{H}$ atoms of $\mathrm{CH}_{2}$ groups and $\mathrm{F}$ atoms of $\mathrm{CF}_{2}$ groups. The vibration band peaks formed at the wave number $1397 \mathrm{~cm}^{-1}, 1402 \mathrm{~cm}^{-1}$ correspond to $\mathrm{CH}_{2}$ wagging of the polymer PVDF-HFP. Further the absorption peaks at $1690 \mathrm{~cm}^{-1}, 1702 \mathrm{~cm}^{-1}$ correspond to doped acids (sulfuric acid). The high degree of sulfonation can occur with sulfuric acid which is favorable for the ionic conduction. The protons are highly mobile in sulfuric acid. Sulfuric acid in the acid doped membranes releases $\mathrm{H}^{+}$, which leads to the protonation of the membranes. Besides, sulfuric acid can be dissociated into $\mathrm{HSO}_{4}^{-}$and $\mathrm{SO}_{4}{ }^{2-}$. It is well known that cations as well as anions enhance the conductivity of the membranes (Dutta et al., 2014). The conductivity of the membranes was measured at temperature ranging from $21^{\circ} \mathrm{C}$ to $115^{\circ} \mathrm{C}$. It is obvious that the proton conductivity of $\mathrm{PVDF}-\mathrm{HFP} / \mathrm{PVA} / \mathrm{TiO}_{2}$ composite membranes is higher than the PVDF-HFP/PVA membrane. Furthermore, the proton conductivity of 


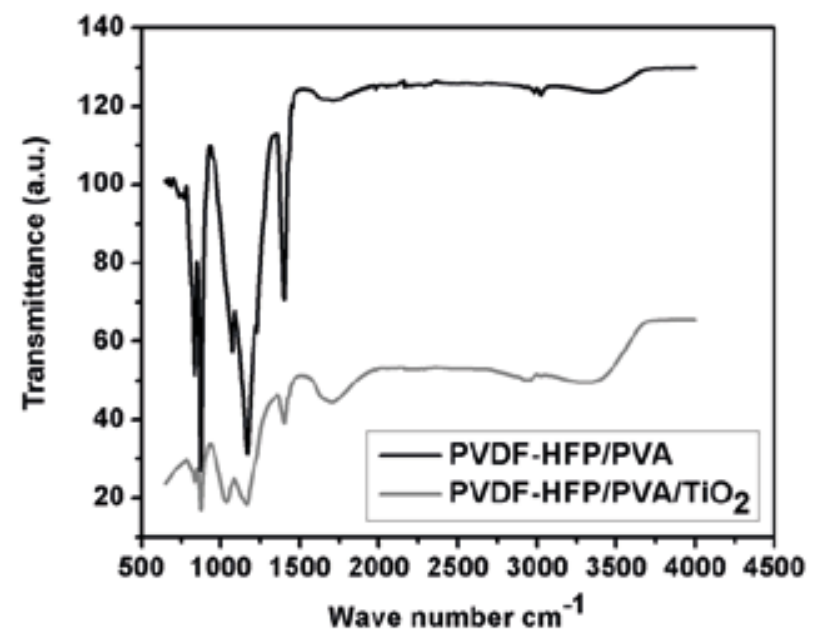

ig. 3. FT-IR spectrum of PVDF-HFP-based composite membranes

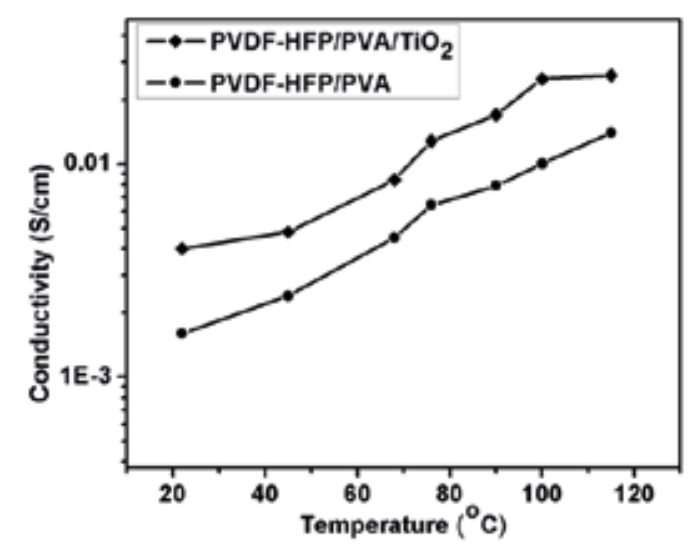

ig. 4. Conductivity of PVDF-HFP-based membranes

PVDF-HFP/PVA/TiO membrane has reached $0.025 \mathrm{~S} / \mathrm{cm}$ at $100^{\circ} \mathrm{C}$. As the $\mathrm{TiO}_{2}$ particle size is sufficiently small, the existing waters of hydration of sulfuric acid may form a bridge between the shrunken clusters, thereby providing a pathway for proton hopping from one cluster to another. In this manner the activation energy for hopping may be reduced (Kumar et al., 2010). The porosity also has a vital role in increasing conductivity. Conductivity of the membrane increased with increasing porosity of the membrane. The increase in temperature influences proton transfer and structural reorganization which results in an increased proton conductivity.
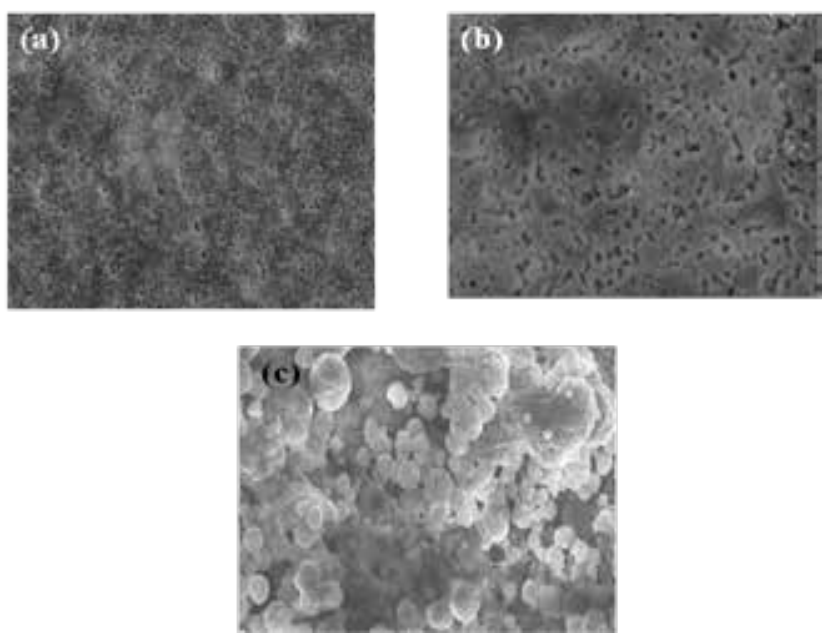

Fig. 5. SEM image of membranes: a. pure PVDF-HFP membrane, b. PVDF-HFP/PVA composite membrane, and c. PVDF-HFP/PVA/TiO, omposite membrane

Surface morphology of pure PVDF-HFP, PVDF-HFP/PVA,

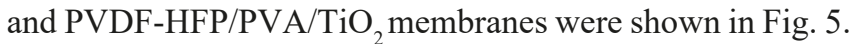
The pure PVDF-HFP membrane surface was presented by Fig. 5 (a) and no porouswas found. The Poly (vinylidene fluoride-hexafluoroprropylene) (PVDF-HFP) copolymer was used as a main back bone polymer for preparing the composites membranes. The uniform pore size distribution throughout the membrane consist of PVDF-HEP/PVA was shown in Fig. 5(b). Since polyvinyl alcohol (PVA) has porogenic properties and in these composite membranes PVA act as a porogenic agent. The PVA was removed by immersion period of $20 \mathrm{~h}$ in water; completely eliminated the porogen agent PVA from the prepared composite membranes. The PVDF-HFP/PVA/TiO ${ }_{2}$ membrane surface morphology was presented in figure 5(c). In the membrane surface, some coagulated structures of $\mathrm{TiO}_{2}$ nanoparticles were found at certain position of the membrane and it favors the acid absorption as shown in Table I. The acid absorption facilitated by large porosity consequently enhances the proton conductivity (Croce et al., 2006).

Fig. 6. shows the methanol permeability as a function of temperature for composite membranes. A proton conducting membrane with lower methanol permeability is required in DMFC. Methanol permeability is the product of diffusion coefficient and sorption coefficient in which the diffusion coefficient reflects the effect of a surrounding environment on the molecular motion of the permeant and the sorption coefficient correlates with the concentration of a component in the fluid phase ((Kumar et al., 2009). The methanol permeability of the polymer membranes with PVDF-HFP matrix decreases obviously compared to Nafion117 


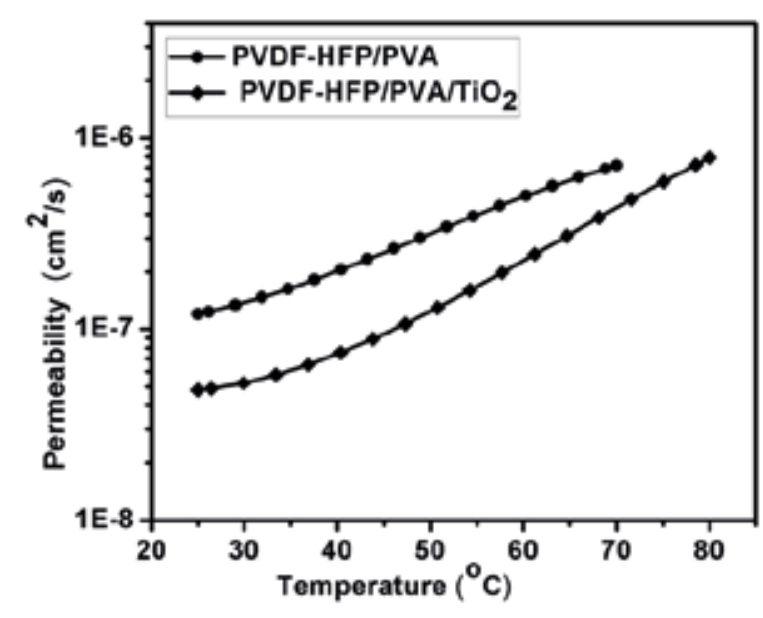

Fig. 6. Methanol permeability of PVDF-HFP-based membranes

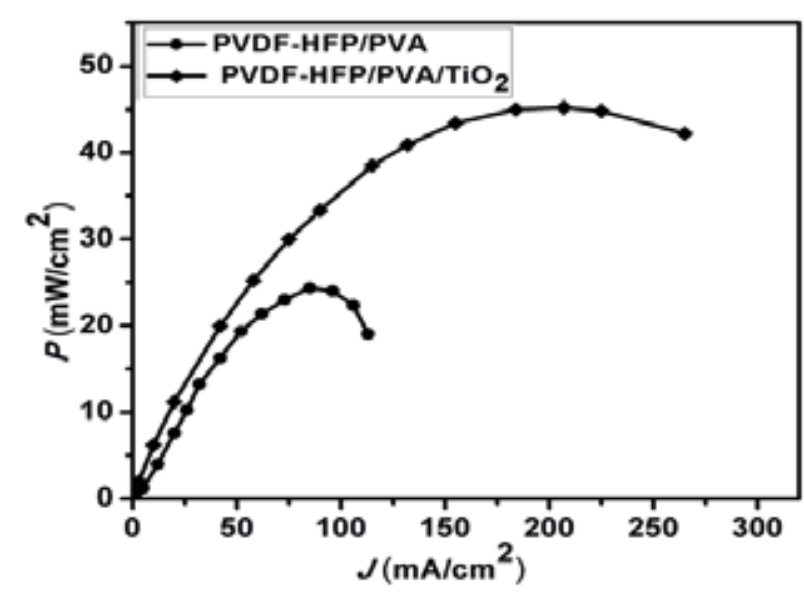

Fig. 7. Power density curves of PVDF-HFP/PVA/TiO and PVDF-HFP/PVA for DMFCs application

membrane which is possibly due to the difference in microstructure between PVDF-HFP and Nafion117 membrane. The hydrophobic nature of the host polymer PVDF-HFP hinders the methanol transport. As a result, low methanol permeability was obtained for all the membranes. On the other hand, the smaller hydrophilic-hydrophobic separation and the lesser flexibility of the polymer backbone of PVDF-HFP produce narrow proton channels and a highly branched structure which baffle the transfer of methanol. In Fig.6, it can also be found that the incorporation of $\mathrm{TiO}_{2}$ causes less methanol permeability because the nanosized dispersion of $\mathrm{TiO}_{2}$ prevents methanol from migrating through the membrane and the covalent cross-linking structure between $-\mathrm{SO}_{3} \mathrm{H}$ of PVDF-HFP and $\mathrm{TiO}_{2}$ leads to the reduction of the ion clusters. Obviously, the results of the proton conductivity and methanol permeability show a good balance of high conductivity and low water and methanol permeability.

Power density curves for MEAs equipped with PVDF-HFP/PVA/TiO ${ }_{2}$ and PVDF-HFP/PVA composite membranes at $80^{\circ} \mathrm{C}$ are shown in Fig.7. It is clearly shown that the performance of the single cell with composite membrane is better. The cell with PVDF-HFP/PVA/TiO composite membrane having higher peak power density of composite membrane reaches $45 \mathrm{~mW} / \mathrm{cm}^{2}$ while the circuit density is $180 \mathrm{~mA} / \mathrm{cm}^{2}$. The higher peak power density indicates a better performance of composite membrane because of its moderate proton conductivity and lower methanol permeability.

\section{Conclusion}

PVDF-HFP/PVA and PVDF-HFP/PVA/TiO 2 composite membranes have been prepared by phase inversion technique to examine usability to DMFC.The dispersion of nano- $\mathrm{TiO}_{2}$ in the membrane increases proton conductivity and has lower methanol permeability than other membranes. But the composite membranes show a good balance in higher proton conductivity and lower methanol permeation. The cell performance shows the cell with PVDF-HFP/PVA/TiO membrane has a high power density than any commercially available membrane, though $\mathrm{TiO}_{2}$ has some influence on the stability of the polymer. Therefore, this membrane is a promising candidate for application in direct methanol fuel cells in future.

\section{Acknowledgement}

This research work was supported by research subsidy for newly-appointed Faculty member of Korea University of Technology and Education, Republic of Korea.

\section{References}

Aricò AS, Bruce P, Scrosati B, Traascon JM and Schalkwijk WV (2005), Nanostructured materials for advanced energy conversion and storage devices, Nat. Mater. 4: 366-377.

Bahlakeh G, Nikazar M and Mahdi Hasani-Sadrabadi M (2013), Understanding structure and transport characteristics in hydrated sulfonatedpoly(ether ether ketone)-sulfonated poly(ether sulfone) blend membranes using molecular dynamics simulations. $J$. Membr. Sci. 429: 384-395. 
Cai Y, Yue Z and Xu S (2017), A novel polybenzimidazole composite modified by sulfonatedgraphene oxide for high temperature proton exchange membrane fuel cells in anhydrous atmosphere, J. Appl. Polym. Sci. 133: 44986-44993.

Chen Y, Guo R, Lee CH, Lee M and McGrath JE (2012), Partly fluorinated poly(arylene ether ketone sulfone) hydrophilic-hydrophobic multiblock copolymers for fuel cell membranes, Int. J. Hydrogen Ener. 37: 6132-6139.

Chae KJ, Kim KY, Choi MJ, Yang E, Kim IS, Ren X and Lee M (2014), Sulfonated polyether ether ketone (SPEEK)-based composite proton exchange membrane reinforced with nanofibers for microbial electrolysis cells, Chem. Eng. J. 254: 393-398.

Cleemann LN, Buazar F, Li Q, Jensen JO, Pan C, Steenberg T, Dai S and Bjerrum NJ (2013), Catalyst Degradation in High Temperature Proton Exchange Membrane Fuel Cells Based on Acid Doped Polybenzimidazole Membranes, Fuel Cells 13: 822-831.

Croce F, Hassoun J, Tizzani C and Scrosati B (2006), Nanoporous composite, low cost, protonic membranes for direct methanol fuel cells, Electrochem Commun 8: 1125-1131.

Dutta K, Das S, Kumar P and Kundu PP (2014), Polymer electrolyte membrane with high selectivity ratio for direct methanol fuel cells: A preliminary study based on blends of partially sulfonated polymers polyaniline and PVdF-co-HFP, Applied Energy 118: 183-191.

Dillon R, Srinivasan SS, Aricó AS and Antonucci V (2004), International activities in DMFC R\&D: status of technologies and potential applications, J. Power Sources 127: 112-126.

Fujiyama S, Ishikawa J, Omi T and Tamai S (2008), SulfonatedPoly(aryl ether ketone) Random Copolymers Having Crosslinking Structure for Proton Exchange Membrane of Fuel Cell, Polymer Journal 40: $17-24$.

Hwang K, Kim JH, Kim SY and Byun H (2014), Preparation of Polybenzimidazole-Based Membranes and Their Potential Applications in the Fuel Cell System. Energies 7: 1721-1732.

Iizuka Y, Tanaka M and Kawakami H (2013), Preparation and proton conductivity of phosphoric acid-doped blend membranes composed of sulfonated block copolyimides and polybenzimidazole, Polym. Int. 62: 703-708.

Jia W, Feng K, Tang B and Wu P (2015), $\beta$-Cyclodextrin modified silica nanoparticles for Nafion based proton exchange membranes with significantly enhanced transport properties, J. Mater. Chem. A3: 15607-15615.

Kumar GG, Lee DN, Kim AR, Kim P, Nahm KS and Elizabeth RN (2008a), Structural and transport properties of porous PVdF-HFP electrolyte membranes modified with an inorganic filler, Composite Interfaces 15: 731-746.

Kumar GG, Nahm KS and Elizabeth RN (2008b), Electro chemical properties of porous PVdF-HFP membranes prepared with different nonsolvents, J. Membr. Sci. 325: 117-124.

Kumar GG, Lee DN, Kim P, Nahm KS and Elizabeth RN (2009), Poly (Vinylidene fluoride-cohexafluoropropylene) /Poly vinyl alcohol porous membranes for the application of fuel cells, J. Polym. Res. 16: 55-61.

Kumar GG, Uthirakumar P, Nahm KS and Elizabeth RN (2009), Fabrication and electro chemical properties of poly vinyl alcohol/para toluene sulfonic acid membranes for the applications of DMFC, Solid State Ionics 180: 282-287.

Kumar GG, So CS, Kim AR, Nahm KS and Elizabeth RN (2010), Effect of Ball Milling on Electrochemical Properties of PVdF-HFP Porous Membranes Applied for DMFCs, Ind. Eng. Chem. Res. 49: 1281-1288.

Li L, Zhang J and Wang YX (2003), Sulfonatedpoly (ether ether ketone) membranes for direct methanol fuel cell. J. Membr. Sci. 226: 159-167.

Liu X, Meng X, Wu J, Huo J, Cui L and Zhou Q (2015), Microstructure and properties of novel SPEEK/PVDF-g-PSSA blends for proton exchange membrane with improved compatibility, $R S C A d v$. 5: 69621-69628.

Miyake J and Miyatake K (2017), Fluorine-free sulfonated aromatic polymers as proton exchange membranes, Polymer Journal 49: 487-495. 
Martinelli A, Matic A, Jaconsson P, Börjesson L, Navarra MA, Fernicola A, Panero S and Scrosati B (2006), Structural analysis of PVA-based proton conducting membranes, Solid State Ionics 177: 2431-2435.

Noshay A and Robeson LM (1976), Sulfonated polysulfone, J. Appl. Polym. Sci. 20: 1885-1903.

Patil AS, Dubois TG, Sifer N, Bostic E, Gardner K, Quah M and Bolton C (2004), Portable fuel cell systems for America's army: technology transition to the field, $J$. Power Sources 136: 220-225.

Prakash GKS, Olah GA, Smart MC, Narayanan SR and Wang QJ (2002), Polymer electrolyte membranes for use in fuel cells, U.S.Pat.US6444343 B1

Qing S, Huang W and Yan D (2005), Synthesis and characterization of thermally stable sulfonated polybenzimidazoles, Eur. Polym. J. 41: 1589-1595.

Rhim JW, Park HB, Lee CS, Jun JH, Kim DS and Lee YM (2004), Crosslinkedpoly (vinyl alcohol) membranes containing sulfonic acid group: proton and methanol transport through membranes, J. Membr. Sci. 238: 143-151.

Staiti P and Minutoli M (2001), Influence of composition and acid treatment on proton conduction of composite polybenzimidazole membranes, J. Power Sources 94: 9-13.

Shen Y, Qiu X, Shen J, Xi J and Zhu W (2006), PVDF-g-PSSA and Al2O3 composite proton exchange membranes, J. Power Sources 161: 54-60.

Tian AH, Kim JY, Shi JY, Kim K and Lee K (2007), Surface-modified Nafion membrane by oleylamine-stabilized $\mathrm{Pd}$ nanoparticles for DMFC applications, J. Power Sources 167: 302-308.
Wang S, Zhao C, Ma W, Zhang G, Liu Z, Ni J, Li M, Zhang $\mathrm{N}$ and $\mathrm{Na} \mathrm{H}$ (2012), Preparation and properties of epoxy-cross-linked porous polybenzimidazole for high temperature proton exchange membrane fuel cells, $J$. Membr. Sci. 411-412: 54-63.

Wu CG, Lu MI and Chang HJ (2005), PVdF-HFP/P123 hybrid with mesopores: a new matrix for high-conducting, low-leakage porous polymer electrolyte, Polymer 46: 5929-5938

Xu H, Chen K, Guo X, Fang J and Yin J (2007), Synthesis of novel sulfonatedpolybenzimidazole and preparation of cross-linked membranes for fuel cell application, Polymer 48: 5556-5564.

Xing P, Robertson GP, Guiver MD, MikhailenkoSD, Wang K and Kaliaguing S (2004), Synthesis and characterization of sulfonatedpoly (ether ether ketone) for proton exchange membranes, J. Membr. Sci. 229: 95-106.

Yamauchi A, Ito T and Yamauchi T (2007), Low methanol crossover and high performance of DMFCs achieved with a pore-filling polymer electrolyte membrane, $J$. Power Sources 174: 170-175.

Yue Z, Cai Y and Xu S (2015), Proton conducting sulfonated poly (imide-benzimidazole) with tunable density of covalent/ionic cross-linking for fuel cell membranes, J. Power Sour. 286: 571-579.

Zhng G, Zhou Z, Li C and Chu H (2009), Proton conducting composite membranes from sulfonated polyether ether ketone and $\mathrm{SiO}_{2}, J$ Wuhan UnivTechnol-Mater. Sci. Ed. 24: 95-99. 